\title{
TI.90.1
}

\section{Security Incident Management Essentials}

- PDF: Security_Incident_Management_Essentials_v4.pdf

- Text:Security_Incident_Management_Essentials_v4.txt

\section{More Information}

\begin{tabular}{|l|l|}
\hline Repository ID & TI.90.1 \\
\hline Persistent URL & http://doi.org/10.26869/TI.90.1 \\
\hline Title & Security Incident Management Essentials \\
\hline Authors & \\
\hline Sponsor & SALSA \\
\hline Review & \\
\hline Status & Legacy \\
\hline Publish Date & August 24, 2009 \\
\hline DOI & $10.26869 /$ TI.90.1 \\
\hline Signature & \\
\hline Deprecated & No \\
\hline Future Review & \\
\hline Supersedes & \\
\hline Format & PDF, Text \\
\hline Related Docs & \\
\hline Development Location & \\
\hline IP Framework & \\
\hline Subject Tags & middlewarerescue \\
\hline Notes & \\
\hline & \\
\hline
\end{tabular}

